\title{
Morphology Evolution and Rheological Behaviors of PP/SR Thermoplastic Vulcanizate
}

\author{
Qiang Wu ${ }^{1,2,3, *} \mathbb{C}$, Jiafeng Fang ${ }^{2}$, Minghuan Zheng ${ }^{2}$, Yan Luo ${ }^{1}$, Xu Wang ${ }^{1, *}$, Lixin $\mathrm{Xu}^{1}$ and \\ Chunhui Zhang ${ }^{3}$ \\ 1 College of Materials Science and Engineering, Zhejiang University of Technology, Hangzhou 310014, China; \\ luoyan@zjut.edu.cn (Y.L.); gcsxlx@zjut.edu.cn (L.X.) \\ 2 College of Engineering, Zhejiang A\&F University, Hangzhou, 311300, China; 18857292977@163.com (J.F.); \\ zmhzafu@163.com (M.Z.) \\ 3 Zhejiang Liniz Advanced Materials Co. Ltd, Hangzhou, 311305, China; soglad@163.com (C.Z.) \\ * $\quad$ Correspondence: wuqiang@zafu.edu.cn (Q.W.); wangxu@zjut.edu.cn (X.W.); Tel.: +86-138-5808-3366 (Q.W.)
}

Received: 11 December 2018; Accepted: 17 January 2019; Published: 19 January 2019

Abstract: The thermoplastic vulcanizates (TPVs) of polypropylene (PP)/silicone rubber (SR) were prepared by dynamic vulcanization (DV) technology. The mixing torque, morphology, viscoelasticity, and creep response of PP/SR TPVs were investigated by torque rheometer, scanning electron microscope (SEM), transmission electron microscope (TEM), rotational rheometer, and dynamic mechanical analysis (DMA). A mixing-torque study showed that torque change and dynamic-vulcanization time increased with SR content increasing in the DV process, but DV rate was independent of SR content. TEM images indicated that the phase inversion of PP/SR-60 TPV from bicontinuous to a sea-island structure took place in the DV process, and a hot press would break the rubber aggregates and shrink a large SR phase. Dynamic-strain measurement demonstrated that PP/SR TPVs exhibit a distinct "Payne effect", which can be attributed to the destruction and reconstruction of SR physical networks. Complex viscosity indicated that SR content did not affect the processability of PP/SR TPVs at high shear rates. Furthermore, the creep deformation and recovery of PP/SR TPVs at solid and melt states were studied, respectively.

Keywords: silicone rubber; polypropylene; thermalplastic vulcanizates; viscoelasticity; creep

\section{Introduction}

Thermoplastic elastomers (TPEs) are polymers that exhibit rubbery properties at using temperature and melt processability above melt temperature. In general, there are two main kinds of TPEs, the block copolymer that has "soft" and "hard" segments, and the thermoplastic vulcanizate (TPV), prepared by dynamic vulcanization, where the curing of rubber occurs during mixing with plastic under a high temperature and shear [1]. Compared with block copolymers, TPV is more suitable for industrial applications. Dynamic-vulcanization (DV) technology was first reported by Gessler and Haslett [2] in 1962, and then further developed by Fischer [3] on polypropylene (PP)/ethylene propylene diene rubber (EPDM) TPVs. PP/EPDM TPVs were finally industrialized by Monsanto in 1981, and are the most studied TPV [4-10]. To achieve high or functional performance, various TPVs were prepared by mixing different plastic phases and rubber phases, such as polyamide 6 (PA6)/EPDM [11-13], PA12/bromobutyl rubber (BIIR) [14], PP/ethylene octene copolymer (EOC) [15,16], poly(lactide) (PLA)/natural rubber (NR) [17], PLA/ethylene-co-vinyl acetate (EVA) [18], PLA/bio-based polyester [19], and thermoplastic polyurethane (TPU)/ NR [20].

Silicone rubber (SR) is an elastomer composed of a $\mathrm{Si}-\mathrm{O}-\mathrm{Si}$ main chain, and widely used in the medical, electronics, construction, automotive, and food fields. Nowadays, due to SR's 
low-temperature flexibility, high-temperature stability, and good biocompatibility, it was selected as a rubber phase to prepare TPVs such as PA/SR [21] and poly vinylidene fluoride (PVDF)/SR TPVs [22,23]. However, almost all SR-containing TPVs were prepared by using a peroxide curing system, which would leave byproducts and become an issue in food contact and medical applications. Besides the peroxide curing system, SR can be crosslinked by a platinum-based curing system, which is also called a hydrosilylation mechanism. The hydrosilylation mechanism refers to the additional reaction of $\mathrm{Si}-\mathrm{H}$ bonds to carbon double bonds borne by poly(dimethylsiloxane) chains in the presence of a platinum catalyst, which has no byproducts and fast curing speed. In addition, compared to PA and PVDF, investigated in previous studies [21-23], PP is a semi-crystalline thermoplastic with good heat, oil, and chemical resistance, outstanding tensile properties, good processability, and low density and cost. Therefore, SR with a platinum-based cure system and PP were chosen to prepare PP/SR TPV by using dynamic-vulcanization technology.

Compared with traditional polymer blends, the preparation of TPVs is more complex due to the simultaneous mixing of various compositions, and the crosslinking and breakup of the rubber phase. The composition ratio, the viscosity ratio of rubber and plastic, and the curing agents (curing rate and extent) could influence the DV process and determine the final morphology and properties of the TPV products. In order to control the final morphology, different feeding procedures $[5,24,25]$ and electron-induced reactive processing [26] were studied. The preparation and microstructure property relationships have been well-reviewed by Ning et al. [1].

Therefore, in order to control the final structure and properties of PP/SR TPVs, morphology evolution and rheological behavior were investigated in this study. The specific objectives included studying the mixing torque and morphology evolution of PP/SR blends at different dynamic-vulcanization stages, and investigating the influence of the PP/SR ratio on the viscoelastic and creep behaviors of PP/SR TPVs.

\section{Materials and Methods}

\subsection{Materials}

The polydimethylvinyl siloxane (PMVS, $M_{\mathrm{W}}=6 \times 10^{5} \mathrm{~g} / \mathrm{mol}$ ), polymethylhydrosiloxane (PMHS, $\left.\eta_{25^{\circ} \mathrm{C}}=80 \mathrm{mPa} \cdot \mathrm{s}\right), \mathrm{Pt}$ catalyst, and alkynol inhibitor were provided by Zhejiang Liniz Advanced Materials Co. Ltd., Hangzhou, China. PP (BA415E, $M_{\mathrm{w}}=5.7 \times 10^{5} \mathrm{~g} / \mathrm{mol}, M_{\mathrm{w}} / M_{\mathrm{n}}=7.0$ ) was purchased from Borealis, Vienna, Austria; its melt temperature was $164{ }^{\circ} \mathrm{C}$, crystalline content was $58 \%$, and flow index was $0.5 \mathrm{~g} / 10 \mathrm{~min}\left(230^{\circ} \mathrm{C}, 2.16 \mathrm{~kg}\right)$. The antioxidant (Irganox 1010) was supplied by Ciba Specialty Chemicals Inc, Basel, Switzerland.

\subsection{Preparation of PP/SR TPVS}

SR was crosslinked by the hydrosilylation mechanism, and the curing reaction of SR can be found in our previous study [27]. PP/SR TPVs with a weight ratio of 70/30, 60/40, 50/50, 40/60 and 30/70 were prepared by using HAAKE PolyLab QC (Karlsruhe, Germany), and were named as PP/SR-30, PP/SR-40, PP/SR-50, PP/SR-60, and PP/SR-70, respectively. All the mixing parameters were carried out at $180^{\circ} \mathrm{C}$ and $80 \mathrm{rpm}$ rotor speed. At first, PP, PMVS, PMHS, alkynol inhibitor, and antioxidant were added and mixed in the chamber. Then, after mix torque reached a stable value, which indicated that the blends were mixed to uniformity, the Pt catalyst was added into the chamber to prepare dynamically crosslinked blends. Until the final stable torque was reached, the blends continued to mix for $3 \mathrm{~min}$. Subsequently, the PP/SR blends were removed. The formulations of PP/SR TPVs are shown in Table 1. The constant volume method of HAAKE was used to prepare the PP/SR TPV samples. Because the chamber volume was $69 \mathrm{~cm}^{3}$, the filling level was $80 \%$, and the density of PP and SR were very close ( 0.9 and $1.0 \mathrm{~g} / \mathrm{cm}^{3}$, respectively), the total weight of each PP/SR TPV formulation was $55 \mathrm{~g}$.

All the specimens for mechanical, rheological, and DMA testing were compression-molded by using a hydraulic press (Daylight Press, Huzhou Dongfang Machinery Company, Huzhou, China). 
First, the PP/SR TPVs were placed into a square mold $(200 \mathrm{~mm} \times 200 \mathrm{~mm})$ with $2 \mathrm{~mm}$ thickness and preheated for $3 \mathrm{~min}$ to melt the $\mathrm{PP}$ at $180^{\circ} \mathrm{C}$; then, the samples were hot-pressed under a pressure of $10 \mathrm{MPa}$ for $8 \mathrm{~min}$, and pressure was released 3 times to remove the bubbles. After the hot press, the samples were placed in another press at room temperature to form. Finally, the PP/SR TPV rectangular sheet was cut into a dumbbell and circular specimens by standard mold knives. The dumbbell specimen was type 4 in ISO 37: 2017 for the mechanical test, and the circular specimens were $25 \mathrm{~mm}$ in diameter for the rheological test. DMA samples were a rectangular strip with $80 \mathrm{~mm} \times 10 \mathrm{~mm} \times$ $2 \mathrm{~mm}$ (length $\times$ width $\times$ thickness).

Table 1. Formulations of the polypropylene (PP)/silicone rubber (SR) thermoplastic vulcanizates (weight ratio).

\begin{tabular}{cccccc}
\hline Sample & PP/SR-30 & PP/SR-40 & PP/SR-50 & PP/SR-60 & PP/SR-70 \\
\hline PP & 70 & 60 & 50 & 40 & 30 \\
PMVS & 30 & 40 & 50 & 60 & 70 \\
Pt catalyst & 0.06 & 0.08 & 0.10 & 0.12 & 0.14 \\
PMHS & 0.9 & 1.2 & 1.5 & 1.8 & 2.1 \\
Alkynol inhibitor & 0.3 & 0.4 & 0.5 & 0.6 & 0.7 \\
Antioxidant & 0.1 & 0.1 & 0.1 & 0.1 & 0.1 \\
\hline
\end{tabular}

\subsection{Characterizations}

\subsubsection{Morphology Characterization}

A TM3030 (Hitachi, Tokyo, Japan) scanning electron microscopy (SEM) was used to study the surface topography of the cryogenic fractured PP/SR TPV specimens. Before SEM observation, the fracture surface was etched by cyclohexane at $100^{\circ} \mathrm{C}$ for $10 \mathrm{~min}$ and ultrasonic-treated to remove the rubber particles. Afterward, the etched surface was coated with gold and subjected to SEM observation.

Transmission electron microscopy (TEM) images of the PP/SR blends were obtained with a JEM-1200EX. A small amount of PP/SR blends (less than $0.2 \mathrm{~g}$ ) at different mixing stages were taken out of the HAAKE chamber and rapidly quenched using liquid nitrogen to fix the phase structure [28]. Then, the samples were sliced into thin films with a thickness of about $100 \mathrm{~nm}$ by using a cryo-ultramicrotome (Leica EM UC7; Germany) at $-150{ }^{\circ} \mathrm{C}$.

\subsubsection{Dynamic Rheological Measurements}

A strain-controlled rheometer (ARES-G2, TA Instruments, New Castle, Delaware, USA), equipped with a plate-serrated fixture $25 \mathrm{~mm}$ in diameter, was used to study the dynamic rheological behavior of PP/SR TPVs. Dynamic strain sweep tests were conducted at a frequency of $10 \mathrm{rad} / \mathrm{s}$ with varying strain, from $0.01 \%$ to $100 \%$ at $200{ }^{\circ} \mathrm{C}$ to find the linear viscoelastic region. The frequency sweep tests were performed from 0.025 to $100 \mathrm{rad} / \mathrm{s}$ at strain amplitude within the linear viscoelastic region of $1 \%$ at $200^{\circ} \mathrm{C}$.

\subsubsection{Creep Measurement}

Creep and its recovery tests were measured by dynamic mechanical analysis (DMA800, TA Instruments, New Castle, Delaware, USA) for PP/SR TPVs in solid state at $40{ }^{\circ} \mathrm{C}$, using ARES-G2 for PP/SR TPVs in melt state at $180^{\circ} \mathrm{C}$. For DMA measurements, PP/SR TPV solid samples were subjected to a constant stress of $1 \mathrm{MPa}$ for $20 \mathrm{~min}$, then recovered for $10 \mathrm{~min}$ by using DMA tension mode at $40^{\circ} \mathrm{C}$. For ARES-G2 measurement, PP/SR TPV melt samples were subjected to a constant stress of $100 \mathrm{~Pa}$ for $200 \mathrm{~s}$, then recovered for $200 \mathrm{~s}$ by using shear mode at $180^{\circ} \mathrm{C}$. 


\section{Results and Discussions}

\subsection{Mixing Torque of PP/SR TPVs}

Figure 1A presents the torque change after the Pt catalyst was added into the chamber. To better describe the torque change of the SR crosslink, the premixing balance torques of PP, PMVS, PMHS, and the antioxidant were normalized to 0 , and the premix processes are not shown here. It can be found that the mixing torque immediately increased and then reached a final stable value after the Pt catalyst was added into the chamber, which indicated the formation of SR phase crosslinking [1]. All the dynamic-vulcanization behaviors of PP/SR blends showed similar torque changes, and the final torque and dynamic-vulcanization time increased with the increase of SR content. Moreover, during the dynamic-vulcanization process, the slopes of torque and time were similar, that is, 10.4, 10.2, 11.1, 10.9 and $11.8 \mathrm{~N} \cdot \mathrm{m} / \mathrm{min}$ for PP/SR-30, PP/SR-40, PP/SR-50, PP/SR-60, and PP/SR-70, respectively. Figure $1 \mathrm{~B}$ shows a good linear relationship between $\mathrm{SR}$ content and torque change or dynamic-vulcanization time. Torque change and slopes corresponded to the vulcanization degree and dynamic-vulcanization rate of the SR phase; hence, it indicated that vulcanization degree and dynamic-vulcanization rate were independent of SR content. This phenomenon also demonstrated that PP did not influence the SR crosslink reaction.
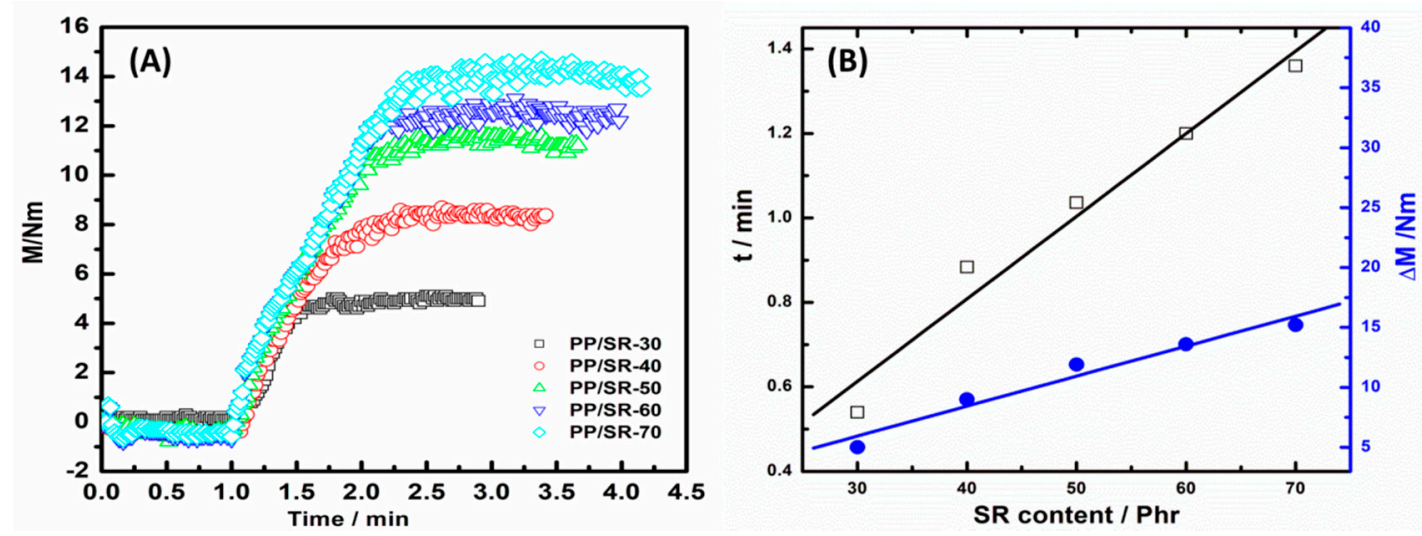

Figure 1. (A) Mixing torque change of polypropylene (PP)/silicone rubber (SR) blends in dynamic vulcanization process and (B) the relationship between SR content and torque change $(\Delta M)$ and dynamic vulcanization time $(t)$.

\subsection{Morphology of PP/SR TPVs}

Figure 2 shows the SEM images of the etched surfaces of PP/SR TPVs and the SR-phase size statistical result. It can be seen in all SEM images that many small holes appeared, represented as the SR phase, due to the SR phase being etched and removed by cyclohexane. The size statistical result found that SR size in the PP/SR TPV was about $0.5 \mu \mathrm{m}$, and was independent of SR content, which may be attributed to the dynamic-vulcanization rate being independent of SR content and the process condition being the same for all PP/SR TPV preparations. Furthermore, Chatterjee et al. [21] and Wang et al. [22] studied PVDF/SR and PA/SR TPVs, and showed similar SEM images of the TPV surface, with an SR size from 0.5 to $8 \mu \mathrm{m}$ and about $2 \mu \mathrm{m}$, respectively. The SR size in our study was much lower than those in their studies, which may be attributed to PP and SR having better compatibility than PVDF/ SR and PA/ SR blends. 

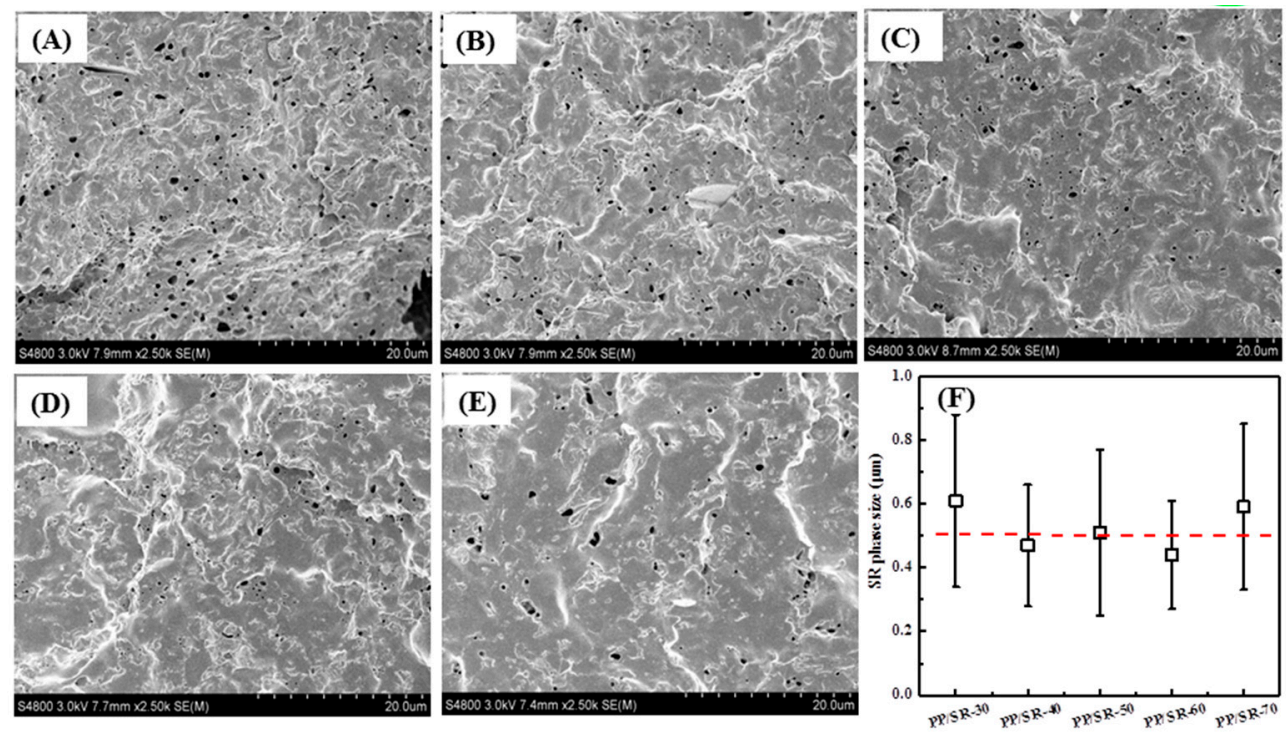

Figure 2. SEM images of etched surfaces for different polypropylene (PP)/silicone rubber (SR) thermoplastic vulcanizates (TPVs). (A) PP/SR-30, (B) PP/SR-40, (C) PP/SR-50, (D) PP/SR-60, (E) PP/SR-70 and (F) SR phase size statistical result.

At different stages of dynamic-vulcanization processing, PP/SR blends exhibited different phase morphologies. Therefore, the PP/SR-60 blend was chosen to study the morphology evolution in processing. According to the torque-change plot of PP/SR-60 prepare process shown in Figure 3A, specimens at two positions ( $\mathrm{B}$ and $\mathrm{C}$ ) were taken out to study the phase morphology. At Position B, PP, PMVS and PMHS were mixed uniformly and the Pt catalyst was not added, which could be used to observe the morphology of the PP/SR-60 blend before dynamic-vulcanization. At Position C, SR was completely crosslinked. To prevent morphology changes, the samples were immediately quenched in liquid nitrogen after being taken out from HAAKE chamber. Figure $2 \mathrm{~B}$ and $\mathrm{C}$ shows the TEM images of PP/SR- 60 at the B and C position; the black part is SR, due to Si having a higher atomic number. The PP/SR-60 blend at Position B showed bicontinuous structure (Figure 2B) and the average phase size was about $0.5-1 \mu \mathrm{m}$. Figure $2 \mathrm{C}$ shows the sea-island structure of the PP/SR-60 blend after dynamic-vulcanization. The SR phase was the dispersed phase, and average size was $2.4 \pm 1.2 \mu \mathrm{m}$, which demonstrated that phase inversion was completed in the dynamic-vulcanization process, and PP/SR-60 TPV was prepared. Moreover, it can be seen that the SR size observed by TEM was larger than that characterized by SEM. This may be attributed to the larger SR phase not being removed by the etching process; hence, SEM images did not show bigger holes (SR phase).

Banerjee's studies found that the rubber phase would decrease to nanosized rubber particles after injection (80 MPa), when they studied polyamide 6/fluoroelastomer TPVs $[29,30]$. Wu et al. also found that the rubber phase in TPV was the aggregates composed by rubber nanoparticles, when they studied EPDM/PP TPVs $[4,28,31]$. Therefore, hot-press molding was subjected to PP/SR-60 TPV to study the influence of the hot press on SR phase size. The mechanical sample that was prepared by hot press was sliced into thin films by cryo-ultramicrotome and used to observe the SR phase size by TEM. Figure 2D shows the morphology of PP/SR-60 TPV after the hot press. Comparing SR morphology in Figure 2C, the large-size SR (in red circles) disappeared, and SR size became smaller and more homogeneous, with the average SR size being $1.6 \pm 0.7 \mu \mathrm{m}$. This may indicate that the SR phase in PP/SR TPV was rubber aggregates that were composed of smaller SR rubber particles, the hot press (10 MPa) could break the rubber aggregates, and make the large SR phase smaller. Furthermore, it should be noted that, because the hot-press molding process had a lower shear rate $\left(1-10 \mathrm{~s}^{-1}\right)$ than that of the injection-molding processes $\left(1000 \mathrm{~s}^{-1}\right)$ in Banerjee's study, the rubber-phase size change was smaller in our study. 


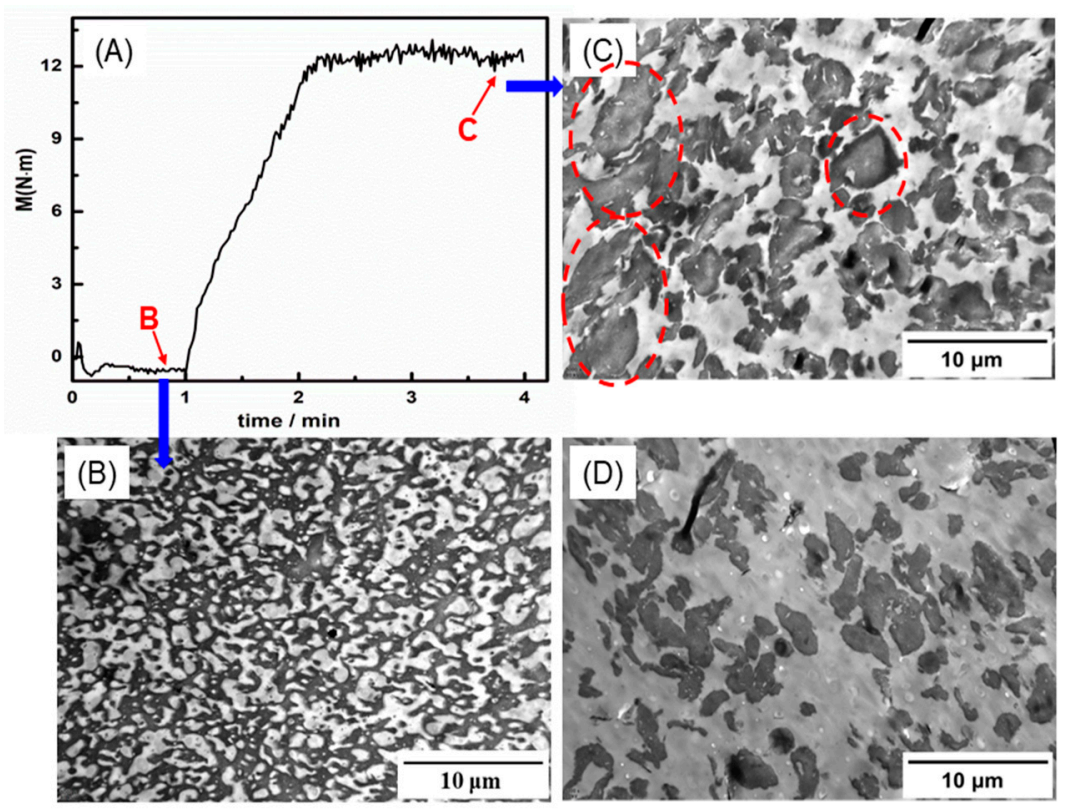

Figure 3. The relationship between different stages of polypropylene (PP)/silicone rubber (SR)-60 preparation and its morphology evolution, (A) Mixing torque change of PP/SR-60 preparation, (B) TEM image of PP/SR-60 blend at point B, (C) TEM image of PP/SR-60 thermoplastic vulcanizate at point C and (D) TEM image of PP/SR-60 TPV after hot press.

\subsection{Strain Sweep of PP/SR TPVs}

Strain sweep was used to determine the linear viscoelastic region of TPVs and microstructure change at different strains [32,33]. Figure $4 \mathrm{~A}$ and $\mathrm{B}$ show the dependence of the dynamic storage modulus $\left(G^{\prime}\right)$ and loss modulus $\left(G^{\prime \prime}\right)$ on the strain amplitude measured at $200{ }^{\circ} \mathrm{C}$ and $10 \mathrm{rad} / \mathrm{s}$ for different PP/SR TPVs. Thermal history and degradation can be neglected for different PP/SR TPV samples because $200^{\circ} \mathrm{C}$ is higher than PP's melt point, and an antioxidant was added in every PP/SR TPV sample. Linear viscoelastic behavior corresponding to strain-independent $G^{\prime}$ was observed at small-strain amplitudes for all samples. As shown in Figure $4 \mathrm{~A}$, a strain of $1 \%$, used in frequency sweep, guaranteed the appearance of linear viscoelasticity under the tested conditions. It was found that the $G^{\prime}$ increased as SR content increased due to SR being crosslinked and exhibiting elasticity in PP/SR TPVs. Moreover, the $G^{\prime}$ decreasing rapidly with increasing strain was called the "Payne effect" in filler-reinforced rubber systems [33-35], and was attributed to the deformation of physical bonds linking adjacent filler clusters. In PP/SR TPVs, there were no covalent bonds between PP and SR, and the SR phase formed a physical SR network in the PP matrix due to the high ratio of SR and their interactions; therefore, the $G^{\prime}$ decreasing with increasing strain should be attributed to the deformation of SR physical networks.

On the other hand, it was noted that G" decreased with the increase of SR content, and the $G^{\prime \prime}$ of PP/SR-60 and PP/SR-70 TPVs displayed a peak with strain in Figure 4B. The G" viscously represented, and PP exhibited a viscous feature in PP/SR TPVs; therefore, the G" decreased with SR content increasing (PP content decreased). The phenomenon of the $G^{\prime \prime}$ showing a peak in strain sweep tests was also well known as the "Payne effect" in rubber rheology studies, which was always attributed to the destruction and reconstruction of particle networks. According to the morphology study in the above section, SR rubbers were aggregates that were composed of smaller SR rubber particles and formed a physical network in the PP matrix; therefore, the G" peak should be related to the destruction and reconstruction of SR rubber-particle aggregates. For high SR content, the SR network was easier to break into small SR aggregates, but also easier to rebuild due to a higher SR ratio (more contact). The breaking and rebuilding of the SR network needs energy, so the G" would increase under proper strains. As the strain continued to increase, the rebuilding SR network became difficult, 
energy loss decreased, and the G" began to decrease. Therefore, the $G^{\prime \prime}$ peak should correspond to the balance of destruction and reconstruction of SR rubber networks.
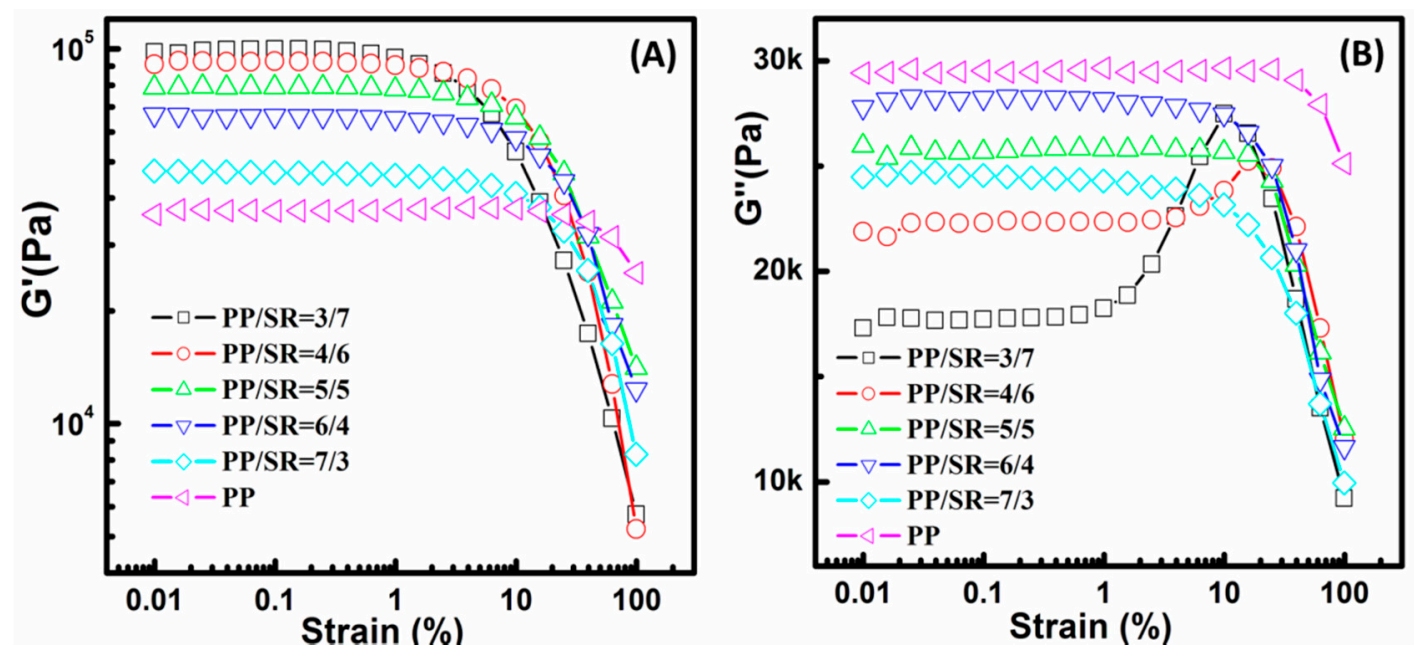

Figure 4. The dependence of the (A) dynamic storage modulus $\left(G^{\prime}\right)$ and $(\mathbf{B})$ loss modulus $\left(G^{\prime \prime}\right)$ on strain amplitude measured at $200{ }^{\circ} \mathrm{C}$ and $10 \mathrm{rad} / \mathrm{s}$ for different polypropylene (PP)/silicone rubber (SR) thermoplastic vulcanizates (TPVs).

\subsection{Viscoelastic Properties of PP/SR TPVs}

Figure 5A and B present the plots of $G^{\prime}$ and $G^{\prime \prime}$ vs. the frequency for PP and PP/SR TPVs with different SR content under $1 \%$ strain at $200{ }^{\circ} \mathrm{C}$. The $G^{\prime}$ increased and the slope of $G^{\prime}$ and $\omega$ at low frequencies decreased as SR content increased due to the elastic SR content increasing and the SR rubber network forming. The change of $G^{\prime \prime}$ was complicated. At a high frequency regime, the $G^{\prime \prime}$ decreased with SR content increasing; at a low-frequency regime, the $G^{\prime \prime}$ increased with SR content increasing. For PP/SR TPVs, the $G^{\prime \prime}$ is related to PP, which exhibits a viscous feature. Therefore, this phenomenon can be attributed to the movement limitation of PP chains by the SR phase. At high frequencies, the movements of PP chains were very small, and SR had little influence on PP chains movements. Hence, G" increased with PP content increasing due to more PP chains moving and consuming energy. At low frequencies, the movements of PP chains were longer, and the limitation of PP chains by SR could not be neglected. The more SR content, the higher constraint on PP chain movements, and the more energy consumed. Hence, the $G$ " increased with SR content increasing.

Figure $5 \mathrm{C}$ shows the dependence of complex viscosity $\eta^{*}$ on frequency. According to the Cox-Merz rule, it can be used to reflect shear viscosity when the values of the shear rate and the oscillation frequency are equal. It can be seen that the $\eta^{*}$ of PP/SR TPVs increased and performed stronger shear thinning behavior with the increase of SR content. At a high-frequency regime, the $\eta^{*}$ of different PP/SR TPVs tended to show similar values, which suggests that high SR content did not affect PP/SR TPVs' processability in extrusion molding, which had a high shear rate or shear stress. 

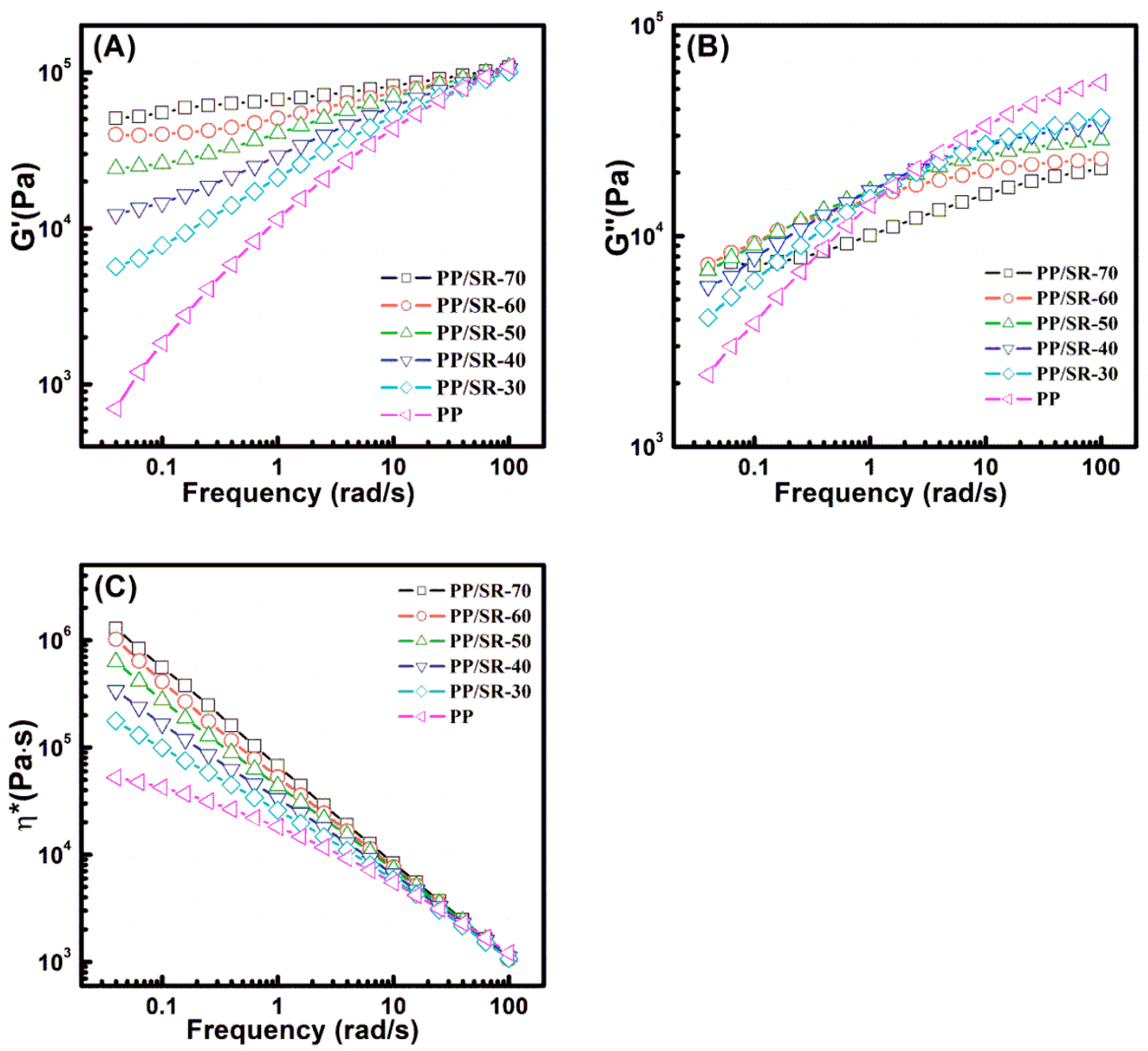

Figure 5. Plots of (A) $G^{\prime},(\mathbf{B}) G^{\prime \prime}$ and (C) complex viscosity $\left(\eta^{*}\right)$ vs. frequency for polypropylene (PP) and PP/ silicone rubber (SR) thermoplastic vulcanizates (TPVs) with different SR content at $200{ }^{\circ} \mathrm{C}$.

\subsection{Creep Behaviors}

Creep is the tendency of materials to deform under stress, which is quite important for the applications of materials requiring long-term durability and reliability. Figure 6A shows the PP/SR TPVs creep deformation and recovery behavior at $40^{\circ} \mathrm{C}$. It can be found that all PP/SR TPVs exhibited a primary creep with a high strain rate, and a secondary creep with a slow strain rate. Then, all PP/SR TPVs showed primary rapid creep recovery and secondary slow creep recovery. This was consistent with creep and its recovery plot for viscoelastic polymers. It also found that creep-deformation and creep-recovery values substantially increased with the increase of SR content, but the recovery rate was very similar for PP/SR TPVs, as shown in Table 2.

On the other hand, Figure $6 \mathrm{~B}$ shows PP/SR TPV melt creep deformation and recovery behavior at $180^{\circ} \mathrm{C}$, and it can be seen that the shear creep-deformation and creep-recovery values decreased with the increase of SR content. For PP/SR-30 TPV, creep deformation and recovery were different from other samples, which can be attributed to PP's melt features. PP was melted and performed viscous features at $180^{\circ} \mathrm{C}$, and the PP/SR-30 sample had more PP content; therefore, it showed larger creep deformation at the same creep time and less recovery than others. Moreover, with SR content increasing, recovery rate increased, reaching $96 \%$, which demonstrated that SR increased the elastic and dimensional stability of the PP/SR TPV melt.

The different creep behavior of PP/SR TPVs at 40 and $180{ }^{\circ} \mathrm{C}$ can be explained as follows. For PP/SR TPVs at $40{ }^{\circ} \mathrm{C}$, the SR had a lower modulus than that of PP; hence, creep deformation of 
$\mathrm{PP} / \mathrm{SR}$ TPVs is determined by SR. The more SR content there is, the higher the creep deformation. However, the creep recoveries of PP/SR TPVs were dependent on the PP, because PP was difficult to recover, so all PP/SR TPVs showed similar recovery rates. For PP/SR TPVs melts at $180^{\circ} \mathrm{C}$, PP had a lower modulus. Therefore, creep deformation of PP/SR TPVs was determined by PP; the less the SR content, the higher the creep deformation. Moreover, SR was crosslinked and exhibited elasticity; hence, with the increase of SR content, the PP/SR TPV melt had a higher recovery rate.
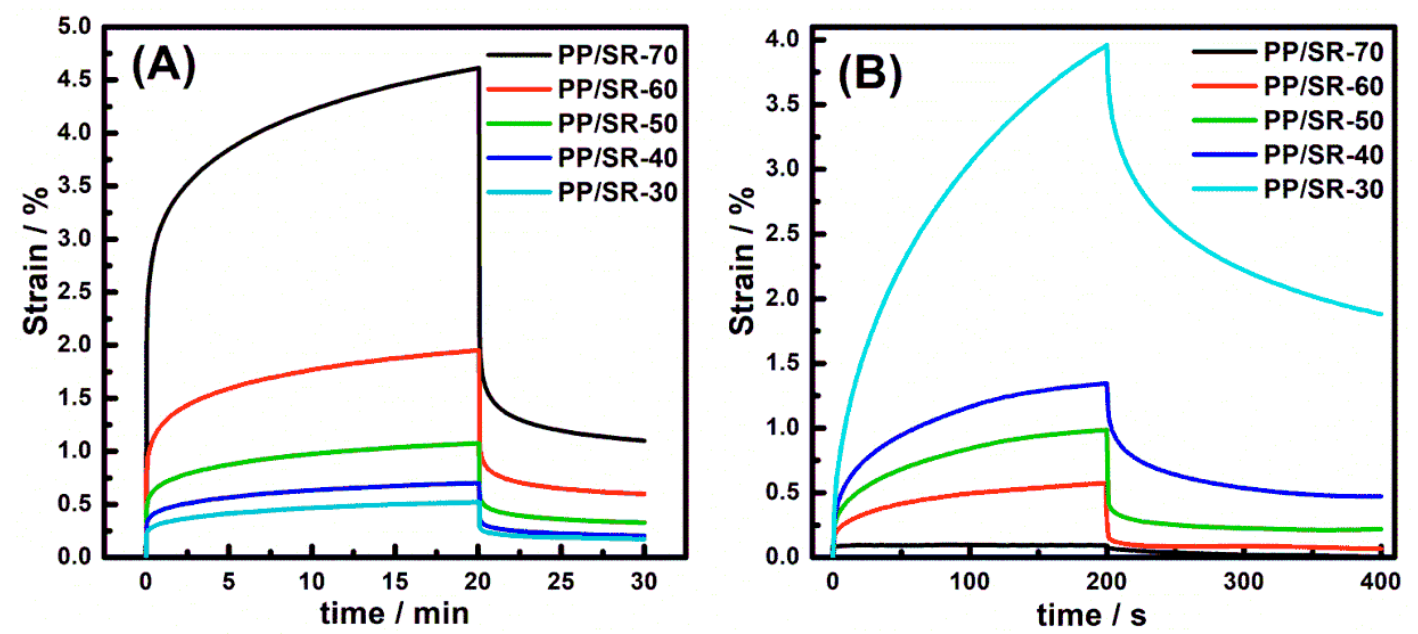

Figure 6. Creep deformation and its recovery behavior of polypropylene (PP)/silicone rubber (SR) thermoplastic vulcanizates (TPVs) at (A) $40^{\circ} \mathrm{C}$ and (B) $180{ }^{\circ} \mathrm{C}$.

Table 2. Creep deformation, creep recovery and recovery rate values of polypropylene (PP)/silicone rubber (SR) thermoplastic vulcanizates (TPVs) at 40 and $180^{\circ} \mathrm{C}$.

\begin{tabular}{|c|c|c|c|c|c|c|}
\hline \multirow[b]{2}{*}{ Samples } & \multicolumn{3}{|c|}{$40^{\circ} \mathrm{C}$} & \multicolumn{3}{|c|}{$180^{\circ} \mathrm{C}$} \\
\hline & $\begin{array}{c}\text { Creep } \\
\text { deformation } \\
(\%)\end{array}$ & $\begin{array}{c}\text { Creep } \\
\text { recovery } \\
(\%)\end{array}$ & $\begin{array}{l}\text { Recovery } \\
\text { rate } \\
(\%)\end{array}$ & $\begin{array}{c}\text { Creep } \\
\text { deformation } \\
(\%)\end{array}$ & $\begin{array}{c}\text { Creep } \\
\text { recovery } \\
(\%)\end{array}$ & $\begin{array}{c}\text { Recovery } \\
\text { rate } \\
(\%)\end{array}$ \\
\hline PP/SR-30 & 0.52 & 0.17 & 67.3 & 3.96 & 1.88 & 52.4 \\
\hline PP/SR-40 & 0.70 & 0.20 & 71.1 & 1.34 & 0.47 & 64.9 \\
\hline PP/SR-50 & 1.08 & 0.33 & 68.7 & 0.98 & 0.26 & 73.4 \\
\hline PP/SR-60 & 1.95 & 0.60 & 69.8 & 0.57 & 0.07 & 88.4 \\
\hline PP/SR-70 & 4.61 & 1.13 & 75.4 & 0.10 & 0.0035 & 96.4 \\
\hline
\end{tabular}

\section{Conclusions}

PP/SR TPVs were prepared by dynamic-vulcanization technology. The mixing torque of PP/SR blends, viscoelastic properties, and creep response of PP/SR TPVs were studied. The size of the SR phase in TPVs was $2.4 \mu \mathrm{m}$ after dynamic vulcanization by TEM observation, but the hot press would break the SR phase and make the large SR phase smaller, which means the SR phase was composed of smaller SR rubber particles and higher shear, being able to make the size of the rubber phase smaller and uniform. PP/SR TPVs showed a distinct "Payne effect", which was attributed to the destruction and reconstruction of SR physical networks. Moreover, creep deformation and its recovery of PP/SR TPVs were dependent on different factors at 40 and $200^{\circ} \mathrm{C}$, respectively.

Author Contributions: Q.W., X.W. and C.Z. conceived the experiments; J.F. and M.Z. performed the experiments; Y.L. and L.X. analyzed the data; Q.W. and J.F. wrote the paper.

Funding: This research was funded by Zhejiang provincial post-doctoral research projects (20170025), National College Students' innovation and entrepreneurship training project (201710341017), Project of National Natural Science Foundation of China (31870548) and Zhejiang Provincial Collaborative Innovation Center for Bamboo Resources and High-efficiency Utilization (2017ZZY2-10). 
Acknowledgments: The authors would like to thank Zhejiang Liniz Advanced Materials Co. Ltd. for their kindly supply of the materials.

Conflicts of Interest: The authors declare no conflicts of interest.

\section{References}

1. Ning, N.Y.; Li, S.Q.; Wu, H.G.; Tian, H.C.; Yao, P.J.; Hu, G.H.; Tian, M.; Zhang, L.Q. Preparation, microstructure, and microstructure-properties relationship of thermoplastic vulcanizates (TPVs): A review. Prog. Polym. Sci. 2018, 79, 61-97. [CrossRef]

2. Gessler, A.M.; Haslett, W.H. Process for Preparing a Vulcanised Blend of Crystalline Polypropylene and Chlorinated Butyl Rubber. US Patent No 3,037,954, 5 June 1962.

3. Fisher, W.K. Thermoplastic Blend of Partially Cured Monoolefin Copolymer Rubber and Polyolefin Plastic. US Patent No 3,862,106, 4 June 1973.

4. Wu, H.G.; Tian, M.; Zhang, L.Q.; Tian, H.C.; Wu, Y.P.; Ning, N.Y.; Chan, T.W. New Understanding of Morphology Evolution of Thermoplastic Vulcanizate (TPV) during Dynamic Vulcanization. ACS Sustain. Chem. Eng. 2015, 3, 26-32. [CrossRef]

5. Ma, L.F.; Bao, R.Y.; Dou, R.; Zheng, S.D.; Liu, Z.Y.; Zhang, R.Y.; Yang, M.B.; Yang, W. Conductive thermoplastic vulcanizates (TPVs) based on polypropylene (PP)/ethylene-propylene-diene rubber (EPDM) blend: From strain sensor to highly stretchable conductor. Compos. Sci. Technol. 2016, 128, 176-184. [CrossRef]

6. Antunes, C.F.; Machado, A.V.; van Duin, M. Morphology development and phase inversion during dynamic vulcanisation of EPDM/PP blends. Eur. Polym. J. 2011, 47, 1447-1459. [CrossRef]

7. Ellul, M.D.; Tsou, A.H.; Hu, W.G. Crosslink densities and phase morphologies in thermoplastic vulcanizates. Polymer 2004, 45, 3351-3358. [CrossRef]

8. Litvinov, V.M. EPDM/PP thermoplastic vulcanizates as studied by proton NMR relaxation: Phase composition, molecular mobility, network structure in the rubbery phase, and network heterogeneity. Macromolecules 2006, 39, 8727-8741. [CrossRef]

9. Naskar, K.; Gohs, U.; Wagenknecht, U.; Heinrich, G. PP-EPDM thermoplastic vulcanisates (TPVs) by electron induced reactive processing. Express Polym. Lett. 2009, 3, 677-683. [CrossRef]

10. Zhao, Y.S.; Liu, Z.W.; Su, B.; Chen, F.; Fu, Q.; Ning, N.Y.; Tian, M. Property enhancement of PP-EPDM thermoplastic vulcanizates via shear-induced break-up of nano-rubber aggregates and molecular orientation of the matrix. Polymer 2015, 63, 170-178. [CrossRef]

11. Oderkerk, J.; de Schaetzen, G.; Goderis, B.; Hellemans, L.; Groeninckx, G. Micromechanical deformation and recovery processes of nylon- 6 rubber thermoplastic vulcanizates as studied by atomic force microscopy and transmission electron microscopy. Macromolecules 2002, 35, 6623-6629. [CrossRef]

12. Oderkerk, J.; Groeninckx, G.; Soliman, M. Investigation of the deformation and recovery behavior of nylon-6/rubber thermoplastic vulcanizates on the molecular level by infrared-strain recovery measurements. Macromolecules 2002, 35, 3946-3954. [CrossRef]

13. Oderkerk, J.; Groeninckx, G. Morphology development by reactive compatibilisation and dynamic vulcanisation of nylon6/EPDM blends with a high rubber fraction. Polymer 2002, 43, 2219-2228. [CrossRef]

14. Ning, N.; Hu, L.; Yao, P.; Wu, H.; Han, J.; Zhang, L.; Tian, H.; Tian, M. Study on the microstructure and properties of bromobutyl rubber ( BIIR)/polyamide-12 (PA12) thermoplastic vulcanizates (TPVs). J. Appl. Polym. Sci. 2016, 133. [CrossRef]

15. Babu, R.R.; Singha, N.K.; Naskar, K. Effects of mixing sequence on peroxide cured polypropylene (PP)/ethylene octene copolymer (EOC) thermoplastic vulcanizates (TPVs). Part. II. Viscoelastic characteristics. J. Polym. Res. 2011, 18, 31-39. [CrossRef]

16. Babu, R.R.; Singha, N.K.; Naskar, K. Effects of mixing sequence on peroxide cured polypropylene (PP)/ethylene octene copolymer (EOC) thermoplastic vulcanizates (TPVs). Part. I. Morphological, mechanical and thermal properties. J. Polym. Res. 2010, 17, 657-671. [CrossRef]

17. Wu, N.J.; Zhang, H.; Fu, G.L. Super-tough Poly(lactide) Thermoplastic Vulcanizates Based on Modified Natural Rubber. ACS Sustain. Chem. Eng. 2017, 5, 78-84. [CrossRef]

18. Ma, P.; Xu, P.; Zhai, Y.; Dong, W.; Zhang, Y.; Chen, M. Biobased Poly(lactide)/ethylene-co-vinyl Acetate Thermoplastic Vulcanizates: Morphology Evolution, Superior Properties, and Partial Degradability. ACS Sustain. Chem. Eng. 2015, 3, 2211-2219. [CrossRef] 
19. Gao, Y.; Li, Y.; Hu, X.; Wu, W.; Wang, Z.; Wang, R.; Zhang, L. Preparation and Properties of Novel Thermoplastic Vulcanizate Based on Bio-Based Polyester/Polylactic Acid, and Its Application in 3D Printing. Polymers 2017, 9. [CrossRef]

20. Kalkornsurapranee, E.; Nakason, C.; Kummerlowe, C.; Vennemann, N. Development and preparation of high-performance thermoplastic vulcanizates based on blends of natural rubber and thermoplastic polyurethanes. J. Appl. Polym. Sci. 2013, 128, 2358-2367. [CrossRef]

21. Chatterjee, T.; Wiessner, S.; Naskar, K.; Heinrich, G. Novel thermoplastic vulcanizates (TPVs) based on silicone rubber and polyamide exploring peroxide cross-linking. Express Polym. Lett. 2014, 8, 220-231. [CrossRef]

22. Wang, Y.; Fang, L.; Xu, C.; Chen, Z.; Chen, Y. Morphology and Properties of Poly(vinylidene fluoride)/Silicone Rubber Blends. J. Appl. Polym. Sci. 2014, 131. [CrossRef]

23. Wang, Y.H.; Gong, Z.; Xu, C.H.; Chen, Y.K. Poly (vinylidene fluoride)/fluororubber/silicone rubber thermoplastic vulcanizates prepared through core-shell dynamic vulcanization: Formation of different rubber/plastic interfaces via controlling the core from "soft" to "hard". Mater. Chem. Phys. 2017, 195, 123-131. [CrossRef]

24. Wang, Y.P.; Jiang, X.J.; Xu, C.H.; Chen, Z.H.; Chen, Y.K. Effects of partial replacement of silicone rubber with flurorubber on properties of dynamically cured poly(vinylidene fluoride)/silicone rubber/flurorubber ternary blends. Polym. Test. 2013, 32, 1392-1399. [CrossRef]

25. Shafieizadegan-Esfahani, A.R.; Abdollahi, M.M.; Katbab, A.A. Effects of Compounding Procedure on Morphology Development, Melt Rheology, and Mechanical Properties of Nanoclay-Reinforced Dynamically Vulcanized EPDM/Polypropylene Thermoplastic Vulcanizates. Polym. Eng. Sci. 2016, 56, 914-921. [CrossRef]

26. Naskar, K.; Gohs, U.; Heinrich, G. Influence of molecular structure of blend components on the performance of thermoplastic vulcanisates prepared by electron induced reactive processing. Polymer 2016, 91, 203-210. [CrossRef]

27. Li, X.; Wu, Q.; Zheng, M.; Li, Q.; Wang, S.; Zhang, C. Mechanical, thermal properties and curing kinetics of liquid silicone rubber filled with cellulose nanocrystal. Cellulose 2018, 25, 473-483. [CrossRef]

28. Wu, H.G.; Tian, M.; Zhang, L.Q.; Tian, H.C.; Wu, Y.P.; Ning, N.Y.; Hu, G.H. Effect of Rubber Nanoparticle Agglomeration on Properties of Thermoplastic Vulcanizates during Dynamic Vulcanization. Polymers 2016, 8. [CrossRef]

29. Banerjee, S.S.; Bhowmick, A.K. Viscoelastic properties and melt rheology of novel polyamide 6/fluoroelastomer nanostructured thermoplastic vulcanizates. J. Mater. Sci. 2016, 51, 252-261. [CrossRef]

30. Banerjee, S.S.; Bhowmick, A.K. Dynamic vulcanization of novel nanostructured polyamide 6/fluoroelastomer thermoplastic elastomeric blends with special reference to morphology, physical properties and degree of vulcanization. Polymer 2015, 57, 105-116. [CrossRef]

31. Wu, H.G.; Tian, M.; Zhang, L.Q.; Tian, H.C.; Wu, Y.P.; Ning, N.Y. New understanding of microstructure formation of the rubber phase in thermoplastic vulcanizates (TPV). Soft Matter 2014, 10, 1816-1822. [CrossRef]

32. Du, M.; Wu, Q.; Zuo, M.; Zheng, Q. Filler effects on the phase separation behavior of poly (methyl methacrylate)/poly (styrene-co-acrylonitrile) binary polymer blends. Eur. Polym. J. 2013, 49, 2721-2729. [CrossRef]

33. Yang, R.Q.; Song, Y.H.; Zheng, Q. Payne effect of silica-filled styrene-butadiene rubber. Polymer 2017, 116, 304-313. [CrossRef]

34. Fletcher, W.P.; Gent, A.N. Non-Linearity in the Dynamic Properties of Vulcanised Rubber Compounds. Trans. Inst. Rubber Ind. 1953, 29, 266-280.

35. Payne, A.R. The dynamic properties of carbon black-loaded natural rubber vulcanizates. Part I. J. Appl. Polym. Sci. 1962, 6, 57-63. [CrossRef]

(C) 2019 by the authors. Licensee MDPI, Basel, Switzerland. This article is an open access article distributed under the terms and conditions of the Creative Commons Attribution (CC BY) license (http://creativecommons.org/licenses/by/4.0/). 